\title{
Principles of Corporeal Pragmatics
}

\author{
Horst Ruthrof \\ English and Philosophy \\ Murdoch University \\ Western Australia \\ ruthrof@murdoch.edu.au
}

\begin{abstract}
In response to recent findings in cognitive linguistics, the paper sums up the principles of 'corporeal pragmatics' as they have been developed so far. At the centre of the author's perceptually oriented investigation of natural language stands the relation between natural language and perception. The paper charges the philosophy of language and linguistics with having for too long committed the sin of Wahrnehmungsvergessenheit, the forgetting of taking for 'true' what our senses tell us. The author proposes to redress this imbalance by an argument that linguistic meaning events rely essentially on the activation of empty linguistic schemata by conceptually regulated, iconic sign materials. Such a claim requires a redefinition of the Saussurean signified, the concept, reference and deixis and other terms in the vocabulary of the study of language. The paper concludes by suggesting that corporeal pragmatics has serious implications for disciplines well beyond philosophy, semiotics, and linguistics.
\end{abstract}

Keywords: Corporeal pragmatics, iconicity, cognitive linguistics, Wahrnehmungsvergessenheit, the corporeal turn, Vorstellung, constraints, nonverbal semiosis, heterosemiotic, implicit deixis

\section{Introduction}

Natural language, this paper argues, is fundamentally related to perception in the broadest sense of the term, both in its linguistic evolutionary history and in its contemporary configurations. If this is so, then we are facing the ironic situation that neither our dominant philosophical nor linguistic paradigms are in a position to account for this relation. True, phenomenology promised some avenues conducive to insights into the relation between language and perception. Sadly, though, they have never been seriously pursued. Husserl's theorisation of appresentation, mental presentations of things absent, (Husserl 1973), Roman Ingarden's elaboration of this notion in the specifics of literary concretisations, (Ingarden 1930;1959), Alfred Schutz's analysis of language as the dominant form of typification (Schutz 1967;1959a;1959b) or Adolf Reinach's speech act phenomenology of 1913 all provided fruitful pointers in the direction of the role which perceptual ingredients play in natural languages, but they failed to inspire more recent philosophers, let alone linguists. Nor have Heidegger's protolinguistic gestures in the context of his remarks of language and interpretation produced a major rethinking relevant to the relation between language and perception (Heidegger 1962). Perhaps the most promising path to perception in language was announced in the work of MerleauPonty under the heading of the primacy of perception. But once again, the enterprise collapsed under the weight of Merleau-Ponty's own self-doubt, or a renewed interest in Husserl's eidetic convictions, or perhaps because of his religious leanings, when he reverted to the concession that language was after all a 'logic in contingency' (Merleau-Ponty 1964:87f.) and that 'there is an essence beneath us, a common nervure of the signifying and the signified' (1968:118; my emphasis). 
Logos rules once more, 'the pre-existent Logos is the world itself' (1962:xx). Thus he terminated the primacy of perception.

A more recent contribution towards a perceptually oriented theorisation of natural language announced itself for a while in some of the French feminist writings, especially those of Luce Irigaray, Helen Cixous, and Julia Kristeva, of which Kristeva's are by far the most significant. In This Sex Which Is not One Irigaray places the tactile at the forefront of her argument about the female experience of language and world, telling us to forget truth and instead acknowledge the prediscursive reality of the body' (Irigaray 1985:89). In 'The Laugh of the Medusa' Helen Cixous likewise argues that woman signifies 'with her body'; women should 'write with their bodies' and so create an 'impregnable language that will wreck partitions, classes, end rhetorics, regulations and codes' (Cixous 1997:351;355). Strong and exciting claims. However, the question arises whether either Irigaray or Cixous have in fact been able to develop a theoretical base strong enough to transcend their Saussurean heritage, which it seems to me remains a powerful obstacle to their own argument (Ruthrof 2000:109-115). If there is a major impulse coming out of French feminist writing for such a review it will probably emerge as a result of Julia Kristeva's psychoanalytic inspiration rather than from a direct engagement with linguistics, including her own work on Saussure (Kristeva 1989). In a very different book, In the Beginning Was Love: Psychoanalysis and Faith (Kristeva 1987) the author for the first time readily and fully embraces the body as an aspect of meaning in order to "develop a powerful model of the human in which language is not divorced from the body; "word" and "flesh" can meet at any moment, for better or for worse' (Kristeva 1987:6). A full, theoretical picture able to fulfil this exciting promise is still to be published.

The third major impulse for a 'corporeal turn' in the theorisation of natural language has come from cognitive linguistics and its neurological research backup. As a result, language philosophy and linguistics, amongst other branches of theorisation, have recently been jolted out of their dogmatic slumber by a number of significant findings in neurologically based research (Gallese and Lakoff 2005; Verhagen 2005; Fauconnier and Turner 2002). Especially the Lakoff School has played a major, though by no means uncontroversial, role in this respect. Barring some of its more overbearing claims and especially its unsustainable anti-philosophical hype, Philosophy in the Flesh: The Embodied Mind and Its Challenge to Western Thought (Johnson and Lakoff 1999) is to be acknowledged as a pioneering case of this kind of research, which attempts to locate the roots of natural language meanings, concepts, and metaphor in the sensory-motor neural functions of the human brain. However successful this challenge will turn out to be, will have to be seen. On thing appears to be certain: we can no longer assume that the relation between natural language and perception is irrelevant to the philosophy of language or linguistics. Unfortunately, many a theorisation of natural language has refused to engage with this relation and so achieved results the positivist precision of which bears little resemblance to what is actually going on in living speech. Their frames of inquiry were conceived too narrowly. Writings which do attempt to account for some of the complexities of natural language, such as theories of speech acts, presuppositions, reference, deixis, and pragmatics very much look like belated attempts at widening the Spanish boots of a too tightly conceived set of starting principles. What is missing in this research is the question of the relation of language and perception, a relation which may very well be at the heart of natural 
language. Once again, positivist research reveals a paradox: precision in description and a certain elegance of argument are marred by too narrow a focus and hence a discrepancy between its results and what actually goes on in the object of inquiry.

Corporeal pragmatics takes its broad methodological research inspiration from a very different tradition: the later parts of Kant's Critique of Judgment. Here we learn that in judging complex phenomena it is appropriate to apply the double strategy of 'reflective' and 'teleological' reasoning, the former which, in contemplating the function of details, is looking for a general law under which they can be understood, the latter stipulating an interpretive umbrella beneath which the detail appears in a larger and meaningful interpretive order (Ruthrof 2004). If this is a good strategy and if the details of natural language only make sense under a broader umbrella that includes perception, then our standard language philosophies and linguistics have for a considerable time been flawed by a collective form of research amnesia, a kind of Wahrnehmungsvergessenheit, or the forgetting of taking for true what we experience with our senses.

\section{Two major impediments to a rich description of language}

Two founders of discourse largely responsible for the elimination of perception and its relation to language are Gottlob Frege and Ferdinand de Saussure. From very different points of departure, the one from mathematical logic, the other from a critique of historical linguistics, Frege and Saussure have left in their wake two separate traditions equally hostile to the investigation of the presence of perceptual ingredients in natural language. In Frege's case, the barring of subjective images from sense marked the beginning of a history of semantics that took its cues increasingly from the domain of formal signification. Having started analytical semantics by analogical reasoning from geometry and arithmetic to a natural language (German in his case), Frege made a radical move: he conflated two kinds of sense, the formal sense of geometry and the kind of sense that characterises such natural language terms as Morgenstern and Abendstern (Frege 1970). Thus he denied the fundamental difference between an a priori sign system for which we first define our terms before we play the formal game and a posteriori signification in natural language, which is spoken, usually for a very long time, before it is described at all. Formal sense can be governed unambiguously by definition, while the dictionaries of natural languages, I argue, have an entirely different function: they guide us to be able to activate the differential system of signifiers and their combinations by way of relating them to our perceptual grasp of our world. The difference between the two kinds of senses could not be any starker. Formal sense can be invented at any time; natural language sense, by contrast, has evolved over a million years, give or take a few, and so carries with it the semantic drift that cannot be separated out from perceptual indication. But perhaps Frege's most influential incision in the history of semantics was his ban of Vorstellung from the description of language, on the grounds that the image which one person may associate with a linguistic expression cannot be identical with someone else's mental, quasi-perceptual associations. Frege's reasoning here rests on the assumption that identity of meaning is as essential to natural language as it is to formally empty propositions, a presupposition that is as erroneous as it is arbitrary. If, for instance, natural language is able to function efficiently on the principle of significant overlap of imagined portions of the world rather than on the principle of identity, Frege's ban of Vorstellung from sense loses much of its apparent cogency. 
It may just be the case that the TV images associated with the notion of ' $\mathrm{UN}$ peace keepers' is entirely sufficient as an intersubjectively shared, nonverbal ground for a common understanding of the meaning of the expression. Let me add here too that the standard translation of Vorstellung as 'idea' is not helpful; it would be more appropriate to translate Vorstellung as 'perception modification' or 'perceptual modification'. Unfortunately, the perceptual side of the German term is likewise lost in the more recent analytical literature which, in the wake of Frege, addresses states of consciousness in terms of 'propositional attitudes'. While propositional acts most likely do play a part in our mental states, they cannot replace the much broader notion of Vorstellung . Such propositional imperialism looks poised to lead us into yet another theoretical icul-de-sac. Of course, Frege cannot be held guilty for the sins of his successors. After all, his goal was no more than the creation of a Begriffsschrift, a modest form of symbolic notation not be taken as the basis for a 'thick' description of natural language (Geertz 1973).

The other major impediment to a rich account of language can be located in the pioneering work of the linguist Ferdinand de Saussure (Saussure 1974). Here too, one has to concede that it is not so much Saussure himself as his inattentive students who recorded his lectures or more likely his successors who must bear most of the blame. And yet, his strong emphasis on differential, syntactic relations paved the way for an increasingly barren description of language as combinatory, as indeed a kind of chess (Saussure 1974:22f.;88f.;110). Even though Saussure had insisted that the signified and signifier played an equally important role, his minimal delineation of the signified as 'image' and 'concept' led to the gradual demise of the signified as 'meaning'. Today, the literature not only in the humanities, but also in some social sciences is full of talk of 'signifiers', as if they themselves were able to be meaningful without signifieds (Laclau 1996). This trend was of course strengthened by Saussure's definition of the linguistic sign as arbitrary, a move that increasingly favoured the signifier to the point where the signified is virtually abandoned, a position which however produces an embarrassing paradox: the arbitrary and empty signifier must now take on the semantic load of the signified, which its very definition does not permit. It is for this reason alone that Saussure's linguistic principle of arbitrariness needs to be revisited. Surprisingly, his generalisation of arbitrariness to cover the linguistic sign as a whole has hardly been challenged, even though, on closer inspection, it rests conspicuously on a fallacious pars pro toto form of reasoning. Because the signifier is arbitrary, Saussure says, therefore the linguistic sign as a whole is likewise arbitrary, which includes the signified as a vital part. Yet there is no argument for the signified to be rightly regarded as arbitrary in the same way as the signifier. Saussure (or his students' notes of his lectures), it would seem, has been rash. As we shall see, a somewhat different conception of the linguistic sign in corporeal pragmatics will produce a markedly different foundation for linguistics altogether. Suffice it here to say that Saussure's syntactic emphasis and rough definition of the linguistic sign have had a detrimental effect on the question of the relation of language and perception. Indeed, the vanishing signified in much contemporary literature is testimony to the diminishing role we now grant the perceptual ingredients of natural language and their modification in Vorstellung. And yet, without Vorstellung and its sedimentation in language we could not at all function as human beings. 


\section{Language and perception}

Taking an evolutionary perspective, the approach to natural language via formal sense and its differential relations or syntax reveals its historical motivation. Both Frege's calculus starting point and Saussure's syntactic emphasis belong firmly to the historical emergence of formal sign systems and scientific structuralism. Having distilled from natural language such formal features as a priori sense and an immanent matrix of differential relations we have now reapplied our findings to describe our non-formal starting point, natural language. It should not be surprising however that language will always yield to the imposition of formal measures, since these very measures were derived from language in the first place. This process of formalisation can be specified as de-referentialisation and de-deictification, both radical reductions of some of the essential perceptual ingredients of language. Predictably, of course, the formal path turns out to be a cul-de-sac: once we have de-materialised the specifics of human speech, the full formalisation bars the return to our starting point, that is, the living speech of natural language.

A very different approach is needed to balance the formal account. To meet the challenge of neurological research, we must now ask the question what role language plays in the larger picture of the survival of humans from pre-linguistic hominids to the present. To do so, I suggest to project a fictional, speculative spectrum stretching from ubiquitous, electromagnetic radiation and its readings by the pre-human organism, nonconscious perception, and perceptual experience to language and its derivatives, such as technical languages, formal sign systems and the digital code. The unifying principles here are information uptake and information processing, features that are shared to different degrees by all stages in this evolutionary process. The opposite principles of differentiation have to do with the varying degree to which, and the semiotic mode in which, information is absorbed, processed and controlled. In such a spectrum we can observe two chiastic, parallel movements, a gradual reduction in information processing and at the same time an increase in control. While information input gradually shrinks along the entire spectrum from non-conscious perception to the Boolean code, our control over the diminishing information increases sharply to the point of electronic mastery of bytes in the digital bitstream. Whereas the early human organism had to evolve under a barrage of excessive radiation, digital machinery is designed for specific quanta of information intake and preconditioned output. For a very long time the biological organism survived, it would seem, by selecting a small band of suitable information from the ubiquitous electromagnetic radiation out of which it constituted its perceptual world (Maud 2003). We now know that it is not our perceptual experience but non-conscious perception that is largely responsible for the way in which we experience our surroundings, the coloured world of objects. After a long phase of perceptual experience, increasingly complex social structures produced, one could speculate, an economisation of perceptual and gestural behaviour. Thus language evolved not at one stroke, as Levy-Strauss has suggested: 'no matter what the moment and the circumstances of its appearance in the animal scale, language could only have been born in a single stroke' (Kristeva 1989:46). Some critics suggest that he didn't quite mean it that way, but in what way did he mean it? Isn't it much more realistic to assume that language, like everything else, gradually evolved as a convenient and necessary economising matrix on top of perceptual communication? Technical languages and their formal cousins appear to be latecomers in this process, with the digital code their most recent descendent. 
In this picture, natural language occupies a central position between perception and formal signification. If this is very roughly so, then it is curious that our dominant theorisations of natural language have persisted on throwing light onto language only from the angle of its own derivatives: formal, propositional approaches. A case of Descartes before the horse?

Sandwiched as it is between perception and its technical derivations, language cannot be adequately described if we forget its perceptual ground. Wahrnehmungsvergessenheit may indeed prove a major obstacle in the search for a linguistics appropriate to its task. What we need to ask beyond the findings by formal and syntactic approaches is what perceptual ingredients have survived in language to this day and in what form and what role they still play. This has not been a popular tack to take. Even as socio-semiotic a linguist as Michael Halliday shares the structuralist belief that in adult language mastery our performance is essentially syntactic (Halliday 1975:141). But perhaps the opposite is the case, as Eve Sweetser has persuasively argued, namely that every term, including function words, reflects perceptual experience (Sweetser 1990). This does not mean that Saussure's differential syntactic relations are not important, what it does mean is that logically prior to syntax language is fundamentally iconic, in the sense that resemblance relations of an aural, tactile, gustatory, olfactory, and visual kind codetermine linguistic meaning. Nor should we forget the emotional dimension of language as a complex nonverbal sign system in its own right (L\#dtke 2006; Trevarthen 2005). In this respect, recent insights in neurological research concerning 'mapping' constitute a seminal moment in the history of language philosophy and linguistics (Fauconnier 1997). No doubt, a corporeal turn is finally in the offing.

\section{Corporeal pragmatics}

What then would a linguistics based on perceptual premises look like? At the moment we do not have a fully fledged, cognitive theorisation of language. In its absence, the following offers a thumb nail sketch of corporeal pragmatics, an attempt at uniting the consequences of the cognitive emphasis on perception with insights from Peircean semiotics and phenomenological investigations into a coherent schematisation. In corporeal pragmatics, language is an empty syntactic matrix, with a meaning potential waiting to be activated. Language by itself does not 'mean'. Every natural language functions because its signifiers are typically paired, as Saussure rightly tells us, with signifieds. Beyond Saussure, this amounts to saying that mental materials, be they iconic or indexical, are ordered by concepts. The signifier-signified connection, however, is not stable nor, as it is in structural linguistics, reliant solely on intergrammatical relations. Rather, the linkage is fundamentally grounded in perceptual signification and so remains tentative, open to historical change, semantic drift, and other meaning transformations. This adds an important dimension to the Saussurean scenario: the differential relations within language are made meaningful by a nonverbal Other, the totality of nonverbal signs. In each meaning event, the language user, guided by the speech community, momentarily stabilises the signifier-signified relation by choosing a specific cluster of nonverbal signs with which to cash in a signifier by a signified. In corporeal pragmatics, then, language is always parasitic on nonverbal semiosis. The question to ask then is how this dependence relation can be made coherent.

To begin with, much of the standard vocabulary in the description of language needs to be revised. Both reference and deixis will have to be redefined as 'inter- 
semiotic' relations (Ruthrof 1997). Nor can there be anything like a semantics of natural language in any strict sense because for meaning to occur at all, that is, for language to function as language, it has to be used, which means it must be activated pragmatically. Even the most abstract 'semantics' handbook is always already a pragmatics. Ironically, and in spite of its misleading name, there cannot be any meaning in such a 'semantics'; it requires a reader to activate its terms by nonverbal means. Only when we fully formalise language, that is, replace each term by a place holder $(x, y)$ can we avoid pragmatic meaning activation in the sense of meaning used here. Yet would we then still speak of a semantics? As Rudolf Carnap has shown, it would make sense in such a case to speak of a 'formal semantics' only if we were to systematically, that is, homosemiotically, pair a fully formal Language 1 with a secondary formal system, Language 2 (Carnap 1975). This suggests that even in a fully fledged formal semantics, a singular language system does not suffice to warrant the term 'semantics'. One could argue that some such pairing also takes place in natural languages, except that here the two semiotic systems to be associated with one another are each of a different kind, they are heterosemiotic: one is verbal, the other nonverbal, iconic. In this sense and contrary to formal sign systems, natural language is in principle always already heterosemiotic.

As we have insisted, in corporeal pragmatics every instance of meaning relies on the practice of iconic realisation. This means that the notion of 'use' always involves mental states and so cannot be equated readily with Wittgenstein's definition. Nonetheless, the Wittgensteinian notion can be accommodated as a secondorder public form of use (Wittgenstein 1953). In corporeal pragmatics, 'use' refers specifically to the event of activation of empty schemata by nonverbal materials ordered into units of iconic signs. The signifier 'slab' is activated by nonverbal signs including a typical size, the memory of a weighty object, the tactile impression of a relatively smooth surface, as well as other visual, tactile, olfactory, proximic, and kinetic readings. These are regulated by a concept and so together constitute the signified of 'slab'. No truth-conditional acrobatics are required to secure meaning; once acquired, our concepts decide for us roughly when sufficient iconic, mental materials have been brought to bear on the empty signifier to render it meaningful. Iconicity is understood here in a broad sense. Peirce's indexical signs are included under the principle of semiotic resemblance relations in the present account on the grounds that they display indirect iconic relations. The fact that indexical signs require more reconstructive interpretive labour than iconic signs affects the principle of resemblance relation only insofar as they foreground Vorstellung, or perceptual modification. What sort of nonverbal iconic materials, then, do we typically engage in the processes of verbal meaning construction? The bulk of our nonverbal signs are made up of olfactory, gustatory, thermal, gravitational, kinetic, aural, emotional, somatic, haptic (internal), tactile (external), and visual readings. In this scenario concepts are defined as social rules regulating linguistic directionality, the kinds of materials to be activated, the required quanta of iconic signs and their combinations, as well as the degree of schematisation to which we abstract iconic contents.

As a rule, in the process of meaning endowment, we do not proceed etymologically, but rather in terms of the current way a culture uses its language. We do not activate 'he is hot under the collar' by recourse to thermal signs, but rather by visual, kinetic, and emotional signs indicating anger. Both the degree of schematisation and the quantity of mental materials effected by the concept in the event of linguistic meaning is to be regarded as a function of sufficient semiosis, the 
communicative boundaries implicit in the specific circumstances of each meaning event. Another characteristic of corporeal pragmatics is the heterosemiotic nature of the activated linguistic signifier. Since the nonverbal materials by which we transform our signifiers are heterosemiotic (olfactory, tactile, auditory, emotive, somatic, etc.) the linguistic sign must have features that act as a regulator assimilating its heterogeneous components. This task cannot be accomplished at the level at which iconic contents are assembled, but rather at a more abstract level, at which different nonverbal sign contents are homogenised. In corporeal pragmatics this function is performed by the concept, not however in its current usage (Margolis and Laurence 1999; Fodor 1998), but as defined below.

Central to corporeal pragmatics is the distinction between COSS (communicative sign systems) and ROSS (read-only sign systems) (Ruthrof 1997). Our perceptual grasp of the world tends to be both a combination of heterogeneous sign readings and a letting others know about our readings. In either case, we are activating various semiotic systems, invariably involving many steps of sign translation. In each case, however, we typically transform an aliquid into an aliquo, the minimal definition of signum. Accordingly, we can distinguish between read-only-signs and communicative signs. The social acts of looking, smelling, tasting, touching and so on are always already potentially both readings and communicative events, which also raises the old question whether we are able to perform nonverbal semiosis without language. That we should be able to do so certainly flies in the face of structuralist accounts, as for instance Saussure's claim that "nothing is distinct before the appearance of language" (Saussure 1974:111). This, of course, is no more than a powerful prejudice. Our distant pre-linguistic ancestors would surely not have survived if their hunting skills had not involved a high degree of precision. Could a pre-linguistic hominid have procreated if it had lived in a 'foggy world'? At this point a certain degree of theoretical fudging comes into play: they may not have spoken a language but their gestures were already linguistic in the sense of a differentially related system of communication. Yet this is no more than a thinly disguised form of linguistic imperialism. Moreover, to call all human semiotic behaviour a 'language' defeats the very point of trying to distinguish natural language from other sign systems, as it does any attempt at trying to argue a significant relationship between verbal and nonverbal semiosis. Here the Peircean semiotic route is by far the better bet. In any case, the structuralist position shows its theoretical weakness also in its failure to account for the experience of not being able to find the appropriate words to describe subtle smell or taste distinctions, the nuances of sexuality, daydreaming, in extreme emotional domains and other areas of human life not well covered by linguistic signs. Cognitive science has shown us that there is indeed a deep chasm between the myriad distinctions even decadent humans are still able to draw in the olfactory, gustatory, and tactile domains and the paucity of the vocabulary relevant to those distinctions in English, as in other languages. In a persuasive study of nonverbal signification, A Natural History of the Senses(Ackerman 1991), the author offers the reader a rich palette of examples of nonverbal readings of the world, providing corporeal pragmatics with ample evidence for the claim that the interaction of perception and language is indeed crucial for a rich description of human speech. But what about linguistic expressions by themselves?

Linguistic expressions and terms by themselves are perceptually empty signifiers that belong strictly to the domain of the dictionary. This is why there are no mean- 
ings in dictionaries. It is the reader who carries meaning into the dictionary by activating its empty schemata with the help of appropriate clusters of nonverbal signs. Nor can the 'as-structures' that characterise dictionaries be called definitions proper, for two reasons. For one, dictionary entries vary in length and detail, a fact that does not square with any strict notion of 'definition'. Second, dictionary entries are typically substitute signifiers, which are collected after the social event of speech. In other words, they are a posteriori descriptions. In formal systems this relation is reversed, where signifier relations function as a priori foundations. Third, the definitions of a formal system neither require nor permit additional mental materials for their activation. The definitions are their necessary and sufficient conditions. Furthermore, formal sign systems have neither reference nor deixis (unless we provide a system of reference as a definitional extra), let alone referential background, and certainly no implicit deixis . By contrast, in natural language, nonverbal ingredients are essential in all these respects. Language points, that is, it is directional and ostensive, a feature it has most likely inherited from its forerunners in gestural protosemiosis. If language is an economizing grid gradually superimposed on earlier forms of gestural communication, it is likely that the principle of inonverbal ostension has survived in language as directionality. In corporeal pragmatics, linguistic signs, that is, combinations of verbal signifiers and conceptually regulated nonverbal sign clusters are argued to act as directional schemata. The speakers of a natural language are trained to associate signifiers and signifieds in such a way that they point in a certain direction in the world as it is realised by a speech community. All linguistic expressions are learned as vehicles of cultural intentionality, the directional agreements shared by the speech community. This includes pragmatic scope, the right kind, size and quantity of the portion of the world selected, the degree of schematisation, as well as sufficiency of indication. If there is lack of clarity, further directional schemata are typically called upon. One could say that in formal sign systems directionality acts like an unambiguous vector, in technical language as a narrow beam, in ordinary social exchange directionality allows for a certain interpretive leeway and negotiation, while in the breakdown of communication directionality becomes ubiquitous or shrinks to zero and so fails.

Linguistics speaks of deixis as a feature marking spatial, temporal, personal and other features of the speech situation, a limited convention in the sense that it addresses only explicit deixis , the tip of the iceberg of general deixis, which includes implicit deixis and also deictic background. The notion of 'ego-centric particulars' in philosophy is subject to the same kind of critique. In corporeal pragmatics every single term of a natural language is typically double-directional, pointing at the same time to its referential aspect and back to its deictic source. Even as simple a preposition as 'on' illustrates this point, indicating as it does simultaneously its referential 'surface contact' and its speaker and utterance position. In other words, language is not just fundamentally referential (as well as self-referential), but also essentially deictic (Bühler 1965). The radical generalisation of the deictic nature of language has serious implications, especially for the description of culture and communication.

\section{Mentalism, subjectivism and social constraints}

Following the advice of Chomsky in his recent return to matters linguistic, meaning in corporeal pragmatics is being described here in a noncontroversial mental sense (Chomsky 2000). The fact of mental states is a sine qua non, one that cannot be 
separated out from the processes that turn signifiers into signifieds. Mental states are indispensable for the event of linguistic meaning. This would not even be denied by supporters of arguments in favour of reducing mental states to the meagre status of 'propositional attitudes', though such a position does little to enlighten us on the question of the relation between language and perception. Nevertheless, the charges of mentalism and subjectivism, to which corporeal pragmatics is even more vulnerable than cognitive linguistics, must be disarmed. Enter the speech community as a set of social constraints on individual linguistic performance. From the first stuttering ventures into the complex field of our mother tongue, every association between signifiers and the conceptually organised nonverbal materials that make up our signifieds is guided not only once but always. Error is thus possible, but is gradually reduced (Trevarthen 1989;2001). On the other hand, this does not mean that the activation of signifiers by iconic signs need be identical in similar speech situations; rather, it only has to be sufficiently similar to guarantee the social functioning of linguistic communication. Thus no two persons of a culture are likely ever to perform identical meaning operations; sufficient overlap is what has to be stipulated. Differences in gender, class, age groups and professions, as well as 'semantic drift', neologisms, intellectual capacity and other factors all qualify as social constraints, as much as they are subject to them.

\section{Other constraints}

Nonetheless, communication rests on members of a speech community making recognisably similar kinds of connections between signifiers and signifieds. They do so on the reciprocal assumption that normally no crassly deviant associations are being formed, an assumption that is supported on the whole by linguistic practice. The relative freedom of experimental poetry only underlines rather than questions this observation. The 'reality check' which every speech community employs to guarantee a reasonable alignment between speech and perceptual reality can be called sufficient semiosis (Ruthrof 1997: 48f.; 2000:140-150). Sufficient semiosis replaces truth-conditions by providing a negotiatory monitoring practice. Speech partners decide whether enough interpretation has occurred, whether there is sufficient promise of mutual understanding to continue a linguistic exchange, or whether it is advisable to terminate the exchange as fruitless. In this practice the question of whether something is the case or not does indeed occur, but has no effect on the problematic of meaning. Simply put: meaning precedes truth. Having said this, there is yet another level of constraint which affects all cultures: the deep constraints of the universe that every culture interested in survival has articulated. No pragmatics can ultimately avoid this metaphysical side of language. The preferred metaphysic of corporeal pragmatics could be described as an autopoietic, inferential realism. This suggests that human beings are organisms that bump into the world in such a way that their nonverbal and, over the last million years or so, also their linguistic responses, optimise survival. The way the human organism respects the deep constraints of the universe is by inferential response. Humans have learnt how to read those constraints as reflected in, or 'shining through', their own signifying practices, verbal as well as nonverbal. This explanatory scheme can be called autopoietic in the sense that humans, like other organisms, are regarded as 'self-creating' in interaction with their immediate environment, their Umwelt (Uexküll 1982; Maturana 1980; Varela 1980;1993). It was Kant who initiated the autopoietic thesis in paragraph 64 of the Critique of Judgment, where he speaks 
of 'ein organisiertes und sich selbst organisierendes Wesen'. The metaphysics of corporeal pragmatics can also be viewed as an inferential realism in the sense that it does not deny the existence of a mind independent universe, with the proviso that whatever we know about it is by way of inferential procedure, another Kantian motif. Inference, however, also plays a powerfully creative role in language in the form of Vorstellung or perceptual modification.

\section{The role of Vorstellung in language}

Vorstellung has for some time had a very bad press in linguistics and language philosophy outside phenomenology. Especially under the onslaught of theories of mental states as 'propositional attitudes' Vorstellung has widely given way to calculus thinking. And yet, Vorstellung as a spectrum of mental performance stretching from the most realist reconstructions of daily experience to the wildest fantasies demonstrably plays a vital role in linguistic practice. Again, it is cognitive research and such non-propositional notions as 'cognitive maps' (Finke 1989), 'mapping' (Fauconnier 1997) and 'conceptual blending' (Fauconnier and Turner 2002; Hutchins 2005) that have reopened the path to the question of what precisely this role could be. In the speculative programme of corporeal pragmatics, Vorstellung is foundational. An embarrassment to post-Saussurean linguists and post-Fregean philosophers alike, the prominence of Vorstellung in natural language is difficult to deny. This is certainly so to the degree to which language draws on, reflects, and expresses typical mental activities. Perceptual modification functions as the Vorstellung of the actual (what we actually taste, smell, touch); in realist representation as the Vorstellung of the absent; in memory as the Vorstellung of the past (e.g. a painful emotion); in prediction as the Vorstellung of the future; in suggestion as the Vorstellung of the tentative; in certitude as the Vorstellung of what seems compelling; in hope as the Vorstellung of what we wish will be the case; in fantasy as the Vorstellung of the possible and impossible; in dream as the Vorstellung of the unconscious; in nightmares the Vorstellung of what is emotionally disturbing and unbearable; in hallucination as the Vorstellung of the counter-factual; in utopia as the Vorstellung of a desirable world; or in dystopia as the Vorstellung of a catastrophic world (Ruthrof 2005). To the extent to which these activities are communicated verbally, Vorstellung is an indispensable, quasi-perceptual ingredient of natural language. It is the engine which puts at our disposal a vast repertoire of nonverbal signs for linguistic activation. To drive home the point of the centrality of Vorstellung as perceptual modification in language and its description in corporeal pragmatics one could characterise language as being no more or less than a set of instructions for how to imagine and act in the world.

\section{Repair work on the linguistic sign}

Given what has been said, the first term to be redefined is the Saussurean linguistic sign itself. In structural linguistics, the linguistic sign is made up of an unmotivated (arbitrary) verbal signifier and an equally unmotivated (i.e., arbitrary) signified. In corporeal pragmatics, the signifier remains the same as in Saussure, except that its arbitrariness is now understood as the result of a long history of 'iconic disembodiment' (Ruthrof 2000:85-97). The signified on the other hand requires serious repair work. It now consists of two elements, a concept and quasi-perceptual, iconic materials, the former acting as a social rule prescribing the kind of nonverbal materials to be drawn on for each signifier. Meaning occurs when empty verbal 
signifiers are activated by iconic signs, producing a signified under the multiple constraints of a concept. In habitual meaning performance, the process of activation happens at synaptic speed; in consciously interpretive meaning events we tend to survey a number of possible signifieds before completing the meaning event or fail to proceed to meaning altogether. This is why the traditional description of conceptuality in propositional terms is unsatisfactory; it fails to account for the time required for interpretive labour. Ironically, this tradition can still be discovered in the otherwise radical revision of the concept in Deleuze and Guattari who believe that the concept occurs at 'infinite speed' (Deleuze and Guattari 1994). In all complex interpretive situations and especially in pedagogy dealing with children and mentally challenged language users this process deserves the most meticulous attention. Having said this, we are now in a position to redefine the signified and its components.

\section{Redefining the concept}

In corporeal pragmatics, the signified now consists of a concept and nonverbal materials, available in the form of iconic signs. In this definition, the signified is no longer a unitary notion but divides into two distinct components, a regulatory concept and the nonverbal materials that allow us to imagine a quasi-perceptual version of a portion of the world. The concept is to be defined as a (1) social, directional rule which determines (2) the kind and (3) quantity of nonverbal, quasi-perceptual materials to be activated in the constitution of the linguistic sign, as well as (4) the degree of schematisation to which those materials are to be transformed to constitute linguistic meaning. In greater detail, the concept functions (1) as a regulator of the direction to which our mental gaze is directed by verbal expressions ("this state of affairs, not that'). This is so because we have learned what to focus on in response to the linguistic expressions of our mother tongue. (2) The concept also regulates the kind of iconic materials we have at our disposal for the activation of empty verbal schema. Typically, iconic signs so regulated are olfactory, gustatory, aural, kinetic, proximic, thermal, gravitational, haptic (internal), tactile (external), emotional, somatic, visual and other nonverbal readings of the world. Such signs can range from preconscious uptakes of electromagnetic radiation processed by the brain without perceptual experience to fully-fledged and consciously experienced clusters of resemblance relations, a point that will prove important once more towards the end of the paper. (3) The concept functions as a regulator of the quantity required for the identification of a verbally indicated item. Having observed that the quantity of iconic signs regulated by concepts is a function of sufficient semiosis, we need to add the qualification that the monitoring effects of sufficient semiosis are subtly adjusted to different circumstances and speech situations. In habitual speech, sufficient semiosis is automated and minimal, hence the impression of 'infinite speed'; in interpretive use, it is as complex as communication requires, and amongst linguistically challenged individuals the process can be laboured, requiring special attention. Such complications may appear to violate the kind of rules we tend to associate with William of Okham. After all, we are only dealing with linguistic meaning. Why are there so many components? Where is the razor? Unfortunately, nothing could be less appropriate to the facts. The sobering insight here is that it is not only the social monitoring processes that are multi-faceted, the sign relations in the process of meaning construction themselves are anything but simple. The iconic signs regulated by concepts as to kind and quantity are not neces- 
sarily suitable for integration into a uniform signified. Iconic signs systems are distinguishable by the kind of biological, perceptual heritage they carry, depending on which of our senses they translate into semiotic units. In other words, the character of different iconic signs reflects the differences between our neurologically distinguishable perceptual realisations. Olfactory signs, for example, are fundamentally heterogeneous if compared with visual signification. Likewise, auditory readings are heterogeneous if compared with gustatory signs, such as specific taste recognitions. This relation is conspicuous in meaning events where the signifiers require activation by iconic signs that belong to perceptual domains normally regarded as incommensurable, as is the case typically in metaphor. Here the meaning event is retarded as a result of the non-linguistic, quasi-perceptual interpretive labour required before the heterosemiotic ingredients can be assembled under a compatible series of signifieds (Ruthrof 1997). Accordingly, we can specify the regulatory task of the concept further: concepts regulate heterosemiotic iconic materials into intersemiotic schematisations. (4) The concept, then, functions also as a regulator of the degree of schematisation to which each meaning event subjects the kind and quantity of iconic signs selected with the help of the concept. The process of schematisation, I suggest, follows the kind of principles discussed by Husserl under the terms of specification and generalisation, on the one hand, and materialisation and formalisation, on the other, two pairs that form the two intersecting axes of all possible abstraction. (Husserl 1969) The degree of abstraction (generalisation or even formalisation) performed by the language user depends primarily on the specifics of the speech situation, language register, discursive domains, genre, and a range of other factors. In philosophical discourse the conceptual schematisation of iconic materials will be typically high, at times to the point of formalisation, while in a story telling situation a good deal of iconicity will be retained to allow Vorstellung (perceptual modification) to produce a richly portrayed slice of world by means of verbal expressions. Yet no matter how schematic or richly iconic our signifieds may be in any given speech event, the fact of iconicity itself is crucial. Corporeal pragmatics here follows the profound Peircean insight that human scale comprehension relies always on the translation of whatever signification we are entertaining into iconic signs, that is, resemblance relations (Peirce 1.158).

\section{Kinds of concepts}

The degree of schematisation of iconic contents is at the heart of the question of how we can reconcile perception and natural language. In the scenario sketched here, the relation between the two varies according to the kind and degree of schematisation of quasi-perceptual materials effected in the linguistic sign as a result of the regulatory work performed by the concept. This at the same time allows us to describe the character of different kind of concepts. Depending on the degree of generality and formalisation, concepts can be distinguished, somewhat arbitrarily, as hard-edged, soft-edged, or soft-core. Hard-edged concepts are formal logical concepts in which deixis and reference are reduced to zero. They also include numerical concepts which display traces of social iconicity (counting). Soft-edged concepts comprise all theoretical concepts governed by definitional descriptions; they have deixis (theoretical perspective) and reference (the kind of world to which they apply), that is, they display curtailed iconicity. Typical concepts in this category are 'differance'; the 'ontic-ontological difference'; 'transcendental reasoning'; 'teleological reason'; the 'differend'; the 'body without organs'; 'the eternal 
recurrence of the same'; and other philosophical notions governed by definitional descriptions without however being strictly formally determined. By contrast, the bulk of natural languages is made up of soft-core concepts which organise iconic materials according to something like Russell's principle of 'vagueness' (Russell 1923). 'Milk', 'running', 'anxiety', 'hollow', 'go-slow strike', 'please help me', as well as prepositions ('on', 'in', 'at') and the function words of natural language (e.g. 'but', 'and', 'if') all require the activation by iconic materials regulated by concepts in order to produce linguistic meaning. Their concepts are regarded as 'soft-core' because they cannot be shown to have either a formal definitional centre, or a Husserlian 'eidetic' essence, or a set-theoretical boundary guaranteeing definitional certitude. What they do display is a roughly shared, or intersubjectively agreed upon 'core' meaning with a sort of meaning 'halo' of diminishing horizonality.

\section{Reviewing reference and deixis as intersemiotic relations}

While we can always add referential and deictic features arbitrarily to any formal sign system, in natural language both reference and deixis are necessary conditions. Moreover, natural language reference and deixis are very different creatures if compared with their logical cousins. To complicate matters, and as the example of Frege's conflation of two kinds of sense showed, natural language in addition also always already has what we can call referential and deictic background. This applies as much to realist speech as to jokes and fictional uses of language, the main difference being that in fictions reference and deixis are constructed by analogy in Vorstellung (perceptual modification) rather than by perceptual assurance. Importantly, in corporeal pragmatics reference and deixis are redefined as intersemiotic relations. This avoids the naïve realism of post-Fregean semantics and the idealism of post-Saussurean linguistics. While the Fregean position is guilty of aligning the sign system of language illegitimately with the object system of the actual world, two incommensurate domains lacking a tertium comparationis, the Saussurean scheme is deficient in the sense that reference and deixis are no more than internal, syntactic relations, which fails to account for how they gear into the nonverbal world of perception. Corporeal pragmatics absolves such aporias by its 'zoo-semiotic' and autopoietic evolutionary starting principles. World and language are aligned on the same plane of abstraction by regarding them as semiotic systems, the world as the sum of iconic signs and language as a heterosemiotic combination of schematised iconicity, conceptual rules, and verbal semiosis. Reference then can be viewed as a relation between verbal expressions and specific clusters of iconic signs with resemblance testable relations to the actual world. Much the same can be said of deixis, redefined as an intersemiotic relation between deictic verbal markers and the iconcity with which we can reconstruct speech situations in the actual world.

\section{Introducing referential and deictic background}

Yet marked or explicit reference and deixis are only the obvious directional devices with which language points beyond itself to a nonverbal reality. From the perspective of meaning construction, by far the more intriguing features of language are their implicit counterparts: referential and deictic background. Here we find ourselves in linguistically uncharted waters. And yet, without sensitive attendance to these two characteristics of natural language we can go badly wrong in meaning 
making, especially in intercultural exchange, such as translation. Not surprisingly, it is such features that further widen the chasm between natural languages and their formal relations. And once again, without iconicity we would be hard pressed to imagine the cultural specifics that make up the referential and deictic background of verbal utterances. Propositional abbreviations will not do and, in any case, can only be achieved after the fact of cultural specificity, such as the typical smells of a regional cuisine and its discourse. These are to be carefully distinguished from specific reference and deixis, which are embedded in such backgrounds. Unlike technical and formal languages, all natural language expressions exhibit this double background in the sense of the kind of world in which both reference (to objects) and deixis (reference to speakers) are interpreted to belong. As such, referential and deictic background is the broad, implicit general nonverbal, semiotic backdrop that is habitually assumed by speakers and readers of a shared culture. To outsiders this tacit knowledge is a major interpretive hurdle. This is why referential and deictic background affect the event of meaning most strongly when we are dealing with cultural difference and the historically distanced text. Referential and deictic backgrounds, then, are essential ingredients of the signified, though typically distributed over whole texts, and both are accessible to language users in a quasi-perceptual manner. Here too, then, Vorstellung as modified perception acts as a bridge between language and world.

\section{Corporeal pragmatics and the 'Myth of the Given'}

The distinction in corporeal pragmatics between iconic readings and concepts is crucial here also for another reason. Iconic readings, nonconscious, conscious, realist and otherwise bridge the traditional, sharp divide between brute reality and conceptual experience, a divide which is as prominent in the philosophical literature as it is dissatisfying (Davidson 1984; Sellars 1956). We are unable as humans, the argument goes, to have access to brute reality without concepts. In other words, concepts block our direct access to the 'Given'. In contrast, corporeal pragmatics proposes arguments for a continuum from electromagnetic radiation to perceptual experience, natural language and beyond language to artificial sign systems, a spectrum that allows us to have it both ways: yes, our biological bodies do have direct access to the 'Given'; and, yes, our conscious experience accesses brute reality with the help of concepts, whereby concepts govern biologically given iconicity. While iconic uptake stretches all the way from the human organism's earliest uptake of ubiquitous radiation and so provided us with a non-consciously accepted coloured object world, concepts kick in at a certain evolutionary phase to add social, cultural control to this biological scenario. In this respect, cognitive linguistics seems to be letting its own side down. While its proposal of the 'embodied concept' respects the continuum, it fails to account for the difference between the biologically given materials, the concept as neural structure and the concept as social production (Lakoff and Johnson 1999). At the same time, the asymmetrical relation between iconic readings and concepts proposed here also places propositional approaches, as for instance Fodor's conceptual atomism, into a broader perspective (Fodor 1998). Fodor's choice of an atomistic conceptual starting point is dangling unsupported in mid air. What is it, corporeal pragmatics asks, that his concept organises? The answer would seem to be 'iconicity', that is the sum of pre-conceptual, biologically provided resemblance relations. Nor are concepts imposed out of the toolbox of a conceptual scheme (Davidson 1984) but gradually and flexibly 
schematise iconic readings for specific conscious, experiential and social purposes. The asymmetrical relation between iconic readings and concepts permits us indeed to have it both ways: our concepts regulate our direct, iconic access to the 'Given' (Sellars 1956). As economising matrix gradually laid over perception, language optimises both principles. What I am suggesting here, then, is that the explanation of human perceptual grasp and natural language along the double axis of iconicity as a pre-linguistic, indeed pre-conscious, human faculty and conceptuality as a social, regulatory function of iconic materials, permits us to transcend the traditional divide of brute reality and human understanding, of what is biologically Given and what is socially constructed.

\section{Conclusion: implications for other disciplines}

At the centre of corporeal pragmatics we have found an elaboration of the Saussurean signified from his minimal indication that 'image' and/or 'concept' are to be seen as components. As it turned out however, the review offered required a much more radical transformation of the Saussurean schema than might have been expected: from an idealistically conceived, self-contained, syntactically driven notion of language into a heterosemiotic, partly biologically and partly socio-culturally constrained picture of natural language. At the centre of corporeal pragmatics we placed iconicity and its regulation by concepts as social rules, a move that permitted the long neglected question of the relation of verbal expressions and perception to be raised as a respectable problematic in the study of natural language. By way of conclusion, the so redefined signified with its conceptually governed iconicity can be argued to have fruitful implication for disciplines well beyond language philosophy, linguistics and semiotics.

What for example does it mean to strive for a 'thick' description of culture, in the sense in which Clifford Geertz introduced the term, if not to write and document the cultural Other in such a way that its iconicity, the resemblance relations of their actual world can be captured as richly as possible? (Geertz 1973). No mere verbiage, less even propositional summaries, can do this kind of job. What is needed are both a language and a conception of language conducive to nonverbal, iconic enrichment. What Geertz has indicated applies to all cultural study, from anthropology to history, literature and cultural studies, to sociology, education, and media studies. Why do students vote with their feet, leaving their linguistics and literature classes for the viewing rooms of media studies? Perhaps because we have managed to theorise the richness of cultural life out of traditional subjects, while iconicity continues to exert its powerful attraction in film. With its emphasis on the nonverbal, corporeal pragmatics may be able to assist in re-invigorating some of the disciplines that have natural language at their core.

\section{References}

Ackerman, Diane, 1991. A Natural History of the Senses. New York: Vintage Books.

Bühler, Karl, 1965. Sprachtheorie: Die Darstellungsfunktion der Sprache [1934] Stuttgart: Gustav Fischer.

Carnap, Rudolf, 1975. Semantics and Formalization of Logic. Cambridge, Mass.: Harvard University Press.

Chomsky, Noam, 2002. New Horizons in the Study of Language and Mind. Cambridge University Press. 
Cixous, Helen, 1997. The Laugh of the Medusa. In Feminisms:An Anthology of Literary Theory and Criticism, ed. Robyn R.Warhol and Diane Price Herndl. (Basingstoke: Macmillan), pp. 347-362.

Davidson, Donald, 1984. On the Very Idea of a Conceptual Scheme. In Inquiries into Truth and Interpretation, ed. Ernest LePore (Oxford: Clarendon Press), pp.183-198.

Deleuze, Gilles and Felix Guattari, 1994. What Is Philosophy? trans. Hugh Tomlinson and Graham Burchell. New York: Columbia University Press.

Fauconnier, Gilles, 1997. Mappings in Thought's Language. Cambridge: Cambridge University Press.

Fauconnier, Gilles and Mark Turner, 2002. The Way We Think: Conceptual Blending and the Mind's Hidden Complexities. New York: Basic Books.

Finke, Ronald, 1989. Principles of Mental Imagery. Cambridge, Mass.: MIT Press.

Fodor, Jerry, 1998. Concepts: Where Cognitive Science Went Wrong. Oxford: Clarendon Press.

Frege, Gottlob, 1970. On Sense and Reference. In Translations from the Philosophical Writings of Gottlob Frege, ed. Peter Geach and Max Black (Oxford: Blackwell), pp.56-78.

Gallese, V. and Lakoff, G., 2005. The Brain's Concepts: The Role of the Sensory-motor System in Reason and Language. Cognitive Neuropsychology, 22 (2005) 455-479.

Geertz, Clifford, 1973. The Interpretation of Cultures: Selected Essays. New York: Basic Books.

Halliday, M.A.K., 1975. Learning How to Mean: Explorations in the Development Language. London: Edward Arnold.

Heidegger, Martin, 1962. Being and Time, trans. John Macquarrie and Edward Robinson. New York: Harper.

Husserl, Edmund, 1973. Cartesian Meditations, trans. Dorian Cairns. The Hague: Martinus Nijhoff.

Husserl, Edmund, 1969. Ideas: General Introduction to Pure Phenomenology, trans. W.R. Boyce Gibson. London: Collier-Macmillan.

Hutchins, E., 2005. Material Anchors for Conceptual Blends. Journal of Pragmatics 37 (2005)1555-1577.

Ingarden, Roman, 1930. Das Literarische Kunstwerk. Tübingen: Max Niemeyer.

Ingarden, Roman, 1959. Vom Erkennen des Literarischen Kunstwerks. Tübingen: Max Niemeyer.

Irigaray, Luce, 1985. The Sex Which Is not One, trans. Catherine Porter. Ithaca: Cornell University Press.

Janssen, T. and G. Redeker (eds.), 1999. Cognitive Linguistics: Foundations, Scope and Methodology. Berlin, Mouton de Gruyter.

Kant, Immanuel, 1968. Kritik der Urteilskraft. Hamburg: Felix Meiner.

Kristeva, Julia, 1989. Language the Unknown: An Initiation into Linguistics, trans. Anne M. Menke. London: Harvester.

Kristeva, Julia, 1987. In the Beginning Was Love: Psychoanalysis and Faith. New York: Columbia University Press.

Laclau, Ernest, 1996. Empty Signifiers. In Emancipation(s). (London: Verso), pp. 36-46.

Lakoff, George and Mark Johnson, 1999. Philosophy in the Flesh: The Embodied Mind and Its Challenge to Western Thought. New York: Basic Books. 
Lüdtke, Ulrike, 2006. Emotion und Sprache: Neurowissenschaftliche und linguistische Relationen. Die Sprachheilarbeit 51 (2006),160-175.

Margolis, Eric and Stephen Laurence (eds.), 1999. Concepts: Core Readings. Cambridge, Mass.: MIT Press.

Maturana, Humberto and Francisco Varela, 1980. Autopoiesis and Cognition: The Realisation of the Living. Dordrecht: Reidel.

Maund, Barry, 2003. Perception. Chesham: Acumen.

Merleau-Ponty, Maurice, 1968. The Visible and the Invisible, trans. Alfonso Lingis. Evanston: Northwestern University Press.

Merleau-Ponty, Maurice, 1964. Signs, trans. Richard McCleary. Evanston: Northwestern University Press.

Merleau-Ponty, Maurice, 1962. Phenomenology of Perception, trans. Colin Smith. London: Routledge and Kegan Paul.

Peirce, Charles Sanders, 1974. Collected Papers of Charles Sanders Peirce, vols 1-6, ed. by Charles Hartshorne and Paul Weiss. Cambridge, Mass.: Harvard University Press.

Putnam, Hilary, 1999. The Threefold Cord: Mind, Body, and the World. New York: Columbia University Press.

Russell, Bertrand, 1923. Vagueness. Australian Journal of Psychology and Philosophy, 1, (1923)84-92.

Ruthrof, Horst, 2008. Language and Perception (forthcoming).

Ruthrof Horst, 2006. Modernity: Vernunftspaltung. Philosophy Today (Fall 2006), 324-337.

Ruthrof, Horst, 2005. The Semiotics of Intercultural Exchange: Ostensive Definition and Digital Reason, Semiotica 157 (2005)1/4, 387-410.

Ruthrof, Horst, 2004. The Fourth Critique. New Literary History 35 (2004)233258.

Ruthrof, Horst, 2000. The Body in Language. London: Cassell.

Ruthrof, Horst, 1997. Semantics and the Body: Meaning from Frege to the Postmodern. Toronto: University of Toronto Press.

Schutz Alfred and Thomas Luckmann, 1973. The Structures of the Life-World, trans. Richard Zaner and H.-Tristram Engelhardt, Jr., Evanston: Northwestern University Press.

Schutz, Alfred, 1967. The Phenomenology of the Social World, trans. George Welsh and Frederick Lehnert. Evanston: Northwestern University Press.

Schutz, Alfred, 1959a. Collected Papers, v.1, ed. Maurice Natanson. The Hague: Martinus Nijhoff.

Schutz, Alfred, 1959b. Type and Eidos in Husserl's Late Philosophy. Philosophy and Phenomenological Research 20 (1959)147-165.

Saussure, Ferdinand de, 1974. Course in General Linguistics, trans. Wade Baskin. London: Fontana.

Sellars, Sellars, Wilfrid, 1956. Empiricism and the Philosophy of Mind. In Minnesota Studies in the Philosophy of Science ed. Herbert Feigl and Michael Scriven (Minneapolis: University of Minnesota Press), pp.253-329.

Sweetser, Eve, 1990. From Etymology to Pragmatics. Cambridge: Cambridge University Press.

Trevarthen, Colwyn, 2005. Action and Emotion in Development of the Human Self, Its Sociability and Cultural Intelligence: Why Infants Have Feelings Like 
Ours. In Emotional Development, ed. J. Nadel and D. Muir (Oxford: Oxford University Press), pp.61-91.

Trevarthen, Colwyn, 2001. The Neurobiology of Early Communication: Intersubjective Regulations in Human Brain Development in Handbook on Brain and Behavior in Human Development, ed. Alex F. Kalverboe and Albert Gramsbergen (Dordrecht: Kluwer), pp.841-882.

Trevarthen, Colwyn, 1989. Signs before Speech. In The Semiotic Web, ed. Thomas A. Sebeok and Jean Umiker-Sebeok (Berlin, New York, Amsterdam: Mouton de Gruyter), pp. 689-755.

Uexküll, Jakob von, 1982. The Theory of Meaning. Semiotica 41-2 (1982)25-82.

Varela, Francisco, Evan Thompson and Eleanor Rosch, 1993. The Embodied Mind: Cognitive Science and Human Experience. Cambridge, Mass.: MIT Press.

Verhagen, Arie, 2005. Constructions of Intersubjectivity. Discourse, Syntax, and Cognition. Oxford: Oxford University Press.

Wittgenstein, Ludwig, 1953. Philosophical Investigations, trans. G.E.M. Anscombe. New York: Macmillan. 